\title{
Convergências e desafios para a pesquisa com imagens em movimento sob a perspectiva da análise do discurso multimodal
}

\author{
Convergences and challenges for the research on moving images from \\ the perspective of multimodal discourse analysis
}

\author{
Graciela Rabuske Hendges \\ Universidade Federal de Santa Maria \\ Roséli Gonçalves do Nascimento \\ Universidade Federal de Santa Maria
}

Resumo: Neste artigo, fazemos uma revisão da literatura (Iedema, 2001; O’Halloran, 2004; Baldry e Thibault, 2007) em Análise do Discurso Multimodal em busca de categorias para segmentação e análise de imagens em movimento em gêneros diversos. 0 objetivo é estabelecer uma análise comparativa entre as propostas e subsidiar tanto a pesquisa quanto o ensino dos multiletramentos por meio de textos em vídeo. A partir da análise, ficou evidente que há um avanço significativo na área, pois os autores investigados apresentam uma sintonia conceitual na proposta de quatro unidades - Quadro, Tomada, Cena e Sequência. Identificamos, entretanto, alguns desafios para futuras pesquisas.

Palavras-Chave: Imagens em movimento. Análise do Discurso Multimodal. Letramentos multimodais.

Abstract: In this paper, we set ou to review the literature (Iedema, 2001; O'Halloran, 2004; Baldry e Thibault, 2007) in Multimodal discourse Analysis in search of categories for segmenting and analysing moving imagens in various genres. The purpose is to establish a comparative analysis across proposals and inform multilitearcies research and pedagogy regarding video texts. From our analysis, it became evident that there has been significant advance in the field, since the reviewed papers converge in proposing four analytical units - Frame, Shot, Scene, and Sequence. However, we have identified a few challenges to be adressed in future studies.

Keywords: Moving images. Multimodal Discourse Analysis. Multimodal literacies. 


\section{GracielaRabuske \\ Hendges \\ Roséli Gonçalves do Nascimento}

\section{Introdução}

Vivemos uma época de alta acessibilidade a textos em vídeo, tanto do ponto de vista do consumo, quanto da produção. Isso é potencializado pelo desenvolvimento e popularização de recursos tecnológicos, tais como aparelhos multifuncionais, programas e mídias para captura, edição e distribuição de vídeos. Esse quadro se associa a um "padrão emergente do discurso" que estimula a construção de significados via combinação entre imagens, simbolismo científico, gestos, ação, música e som" (O'HALLORAN, 2004). Nessa configuração tecnológica e social, os modos de se comunicar são influenciados tanto pela diversidade linguística quanto pela diversidade cultural (THE NEW LONDON GROUP, 1996) e demandam o desenvolvimento dos multiletramentos, ou seja, habilidades para se engajar em uma variedade de formas textuais associadas às tecnologias de produção e distribuição da informação e formas de representação em diferentes contextos.

Dentre os múltiplos letramentos, destacamos, para fins deste artigo, os letramentos multimodais, aqueles que envolvem a compreensão dos diversos modos de representar o conhecimento e de construir sentido (JEWITT; KRESS, 2003), e os "letramentos metamidiáticos", ou seja, a capacidade de configurar as informações para uma mídia e de recontextualizá-las de uma outra(s) mídia(s) (LEMKE, 2010), levando em consideração os modos de comunicar, as mídias propriamente ditas e as linguagens que essas mídias suportam para constituir textos em contextos particulares.

A escola é um dos contextos nos quais esses letramentos são ou deveriam ser explorados. Para atender a um mundo em transformação e à diversidade cultural dos alunos, devemos valorizar e integrar tais letramentos na prática pedagógica (COPE; KALANTZIS, 2009; ALBERS; SANDERS, 2010), particularmente na área das linguagens, códigos e suas tecnologias. Em nosso grupo de pesquisa, temos investigado gêneros em vídeo, tais como artigos acadêmicos audiovisuais, filmes, fábulas, comerciais de TV e videoclipes musicais, considerando seu potencial para o ensino de inglês como língua estrangeira/adicional.

Para subsidiar o ensino de letramento multimodal de textos em vídeo, entendemos que é necessário desenvolver teoria e metalinguagem que nos permitam nomear, manipular e avaliar essa modalidade de texto em suas particularidades. No campo da Análise do Discurso Multimodal (doravante $\mathrm{ADM}$ ), o número de estudos que abordem questões de metodolo- 
gia para análise de imagens em movimento ainda é pequeno se comparado àqueles que investigam imagens estáticas. Na Gramática do Design Visual (GDV), por exemplo, Van Leeuween, 1996 e Kress and Van Leeuwen (1996; 2006) enfocam imagens estáticas e descrevem as imagens em movimento de forma breve no que tange à aplicabilidade das categorias da gramática visual para recursos semióticos além da imagem estática.

$\mathrm{Na}$ área de ADM, três estudos se destacam ao propor categorias que subsidiem a análise de textos em vídeo sob uma perspectiva funcional: Iedema (2001), O'Halloran (2004) e Baldry e Thibault (2007) ${ }^{1}$. Esses estudos recontextualizam categorias da GDV (KRESS; VAN LEEUWEN, 1996; 2006) no intuito elucidar como construímos significado por meio da combinação de múltiplos recursos semióticos (palavra, som, imagem, gesto) em um mesmo artefato. Na GDV, o conceito de gramática, como observam Kress e Van Leeuwen (2006), é de base descritiva, isto é, busca descrever como o processo de construção de significados é dinâmico, de modo que determinadas estruturas visuais são culturalmente associadas a valores e funções. A GDV propõe ferramentas para descrevermos a forma como itens identificáveis visualmente tais como "pessoas, lugares e coisas" são arranjados em orações visuais de maior ou menor complexidade e extensão (KRESS; VAN LEEUWEN, 2006, p. 1). A questão da delimitação de uma unidade semântica em imagens estáticas não impõe maiores dificuldades para o analista, visto que os elementos estão todos circunscritos a um enquadramento fixo no espaço e no tempo. A imagem em movimento, por sua vez, é menos estável e segue uma lógica temporal.

Nesse sentido, o presente artigo visa contribuir para a sistematização do conhecimento no que tange à análise de imagens em movimento ao empreender uma revisão das propostas de Iedema (2001), O'Halloran (2004) e Baldry and Thibault (2007). Nosso propósito é identificar pontos de convergência e divergência entre as propostas de Iedema (2001), O'Halloran (2004) e Baldry and Thibault (2007) no que se refere a categorias analíticas e critérios para identificação e delimitação de unidades de análise de imagens em movimento. Pretendemos, ao longo da discussão, exemplificar o potencial de aplicação dessas categorias para análise dos gêneros investigados no âmbito de nosso grupo

1 Outra abordagem recente para análise "documentos com imagens não estáticas" é proposta por Bateman (2013) com base no modelo Gênero e Multimodalidade (GeM) e não na Linguística Sistêmico Funcional. A despeito de sua relevância, essa proposta não será revisada aqui por questões de tempo e espaço. 
GracielaRabuske

Hendges

Roséli Gonçalves

do Nascimento

de pesquisa. Este artigo elabora uma iniciativa concebida e apresentada em uma comunicação oral (NASCIMENTO; HENDGES, 2014) e explorada em um trabalho de final de graduação (XAVIER, 2016), sob orientação e avaliação das autoras.

Os estudos de Iedema (2001), O'Halloran (2004) e Baldry and Thibault (2007) foram selecionados devido à sua afiliação teórica com a linguística sistêmico funcional (Halliday) e com a ADM. O estudo da interação do texto com o contexto social é um princípio básico para as três propostas, e a principal inovação que apresentam é a identificação de categorias que permitem a segmentação das imagens em movimento.

Sendo assim, neste artigo, faremos uma revisão dos textos 1) de Rick Iedema (2001), intitulado Analyzing Film and Television: a Social Semiotic Account of Hospital: an unhealthy business, no qual o autor analisa um documentário sobre a rotina de um hospital; 2) de Kay L. O’Halloran (2004), intitulado Visual Semiosis in Film, no qual a autora propõe categorias para análise de filmes apliacadas à obra Chinatown'; 3) de Baldry e Thibault (2007), intitulado Multimodal Transcription and Text Analysis, que oferece categorias para segmentação e análise de imagens em movimento, especialmente do gênero comercial televisivo.

O objetivo deste artigo é estabelecer uma análise comparativa das categorias elaboradas por esses autores, delinear uma proposta de síntese e apontar a aplicabilidade desta para o parcelamento e análise do sentido de imagens em movimento nos trabalhos desenvolvidos em nosso grupo de pesquisa, conforme indicado anteriormente.

Para tanto, iniciamos por identificar a terminologia adotada nos três estudos. A seguir, buscamos as definições apregoadas para cada termo e sua relação com as demais categorias em cada proposta. A partir disso, propomos uma articulação entre os três modelos e suas categorias a partir da identificação de equivalências e divergências.

0 resultado dessa articulação foi sistematizado na forma de um modelo conjugado para análise de imagens em movimento em termos de unidades analíticas. As categorias foram ilustradas e sua aplicabilidade tencionada por meio de exemplos de diversos gêneros em análise pelo grupo de pesquisa.

2 Filme neo-noir estadunidense de1974, dirigido por Roman Polanski, estrelado por Jack Nicholson, Faye Dunaway e John Huston e produzido por Robert Evans para a Paramount Pictures. Apresenta muitos elementos de filme noir, particularmente uma história multicamadas que varia entre a necessidade de solucionar um mistério e a narrativa de um drama psicológico. 
O software livre Windows Movie Maker foi utilizado para manipular os vídeos.

\section{Categorias para análise de imagens em movimento}

Considerando os três trabalhos revisados neste estudo - Iedema (2001), O'Halloran (2004) e Baldry e Thibault (2007) -, o primeiro aspecto que destacamos é que cada qual discute imagens em movimento a partir da perspectiva de seu objeto de análise. Essa diferença pode ter consequências na definição das categorias.

A própria definição do termo "imagens em movimento" não é desenvolvida pelos autores. Baldry e Thibault (2007) associam o termo a “tecnologia de vídeo", enquanto Iedema (2001) e O’Halloran (2004) utilizam o termo subordinado "filme", uma vez que examinam um documentário e um neo-noir, respectivamente. A ausência de uma explicação explícita sobre o conceito de "imagem em movimento" provavelmente se deve ao objetivo em comum entre os autores, que é ilustrar como as categorias da GDV podem ser estendidas para a análise de textos nesse formato.

Um dos princípios subjacentes à metodologia adotada nos três trabalhos é o da constituência. $O$ conceito de constituência (tradução livre de constituency a partir de literatura da área - GOUVEIA, 2009), conforme proposto por Halliday (2004), refere-se a relações parte-todo entre as unidades linguísticas que realizam um texto ${ }^{3}$. Unidades de um nível hierárquico superior são compostas por unidades de um nível inferior. Ao utilizar esse conceito, é possível reconhecermos os componentes da linguagem e compreendermos como eles se integram na construção do significado (HALLIDAY; MATTHIESSEN, 2004, p 5-7). A linguagem verbal escrita, por exemplo, organiza-se nos seguintes componentes, em ordem decrescente de hierarquia: complexos oracionais, orações, grupos, palavras e morfemas (Figura 1).
Convergências e desafios para a pesquisa com imagens em movimento sob a perspectiva da análise do discurso multimodal

3 É preciso esclarecer que, tecnicamente (HALLIDAY; MATTHIESSEN, 2004, p. 587), não dizemos que um texto (escrito) é constituido de orações; não há uma relação de parte-todo entre oração e texto. Ao invés disso, dizemos que um texto é realizado por orações, já que cada qual pertence a um plano comunicativo diferente: o texto, ao plano da semântica, e as orações, ao plano da lexicogramática. 


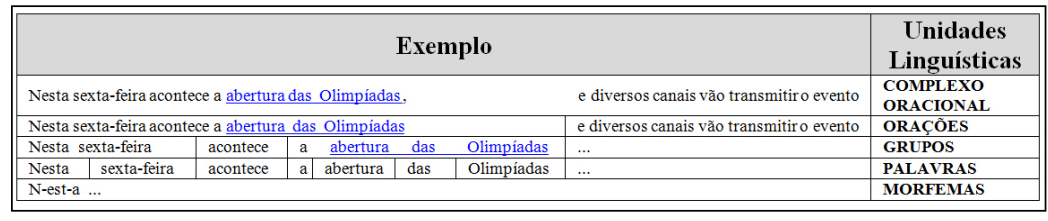

GracielaRabuske

Hendges

Roséli Gonçalves

do Nascimento

Figura 1. Constituência na linguagem verbal escrita

Os três estudos revisados, entretanto, tomam o princípio da constituência como uma noção subentendida. Apesar de Iedema (2001) e O'Halloran (2004) trazerem uma descrição detalhada dos níveis que propõem para o estudo de imagens em movimento, nehnhum dos três trabalhos problematiza o sistema de níveis que adota. Por essa razão, tais estudos oferecem mais dados para a presente análise. Ainda assim, nas propostas de Iedema (2001) e O'Halloran (2004), que apresentam maior detalhamento, podem gerar dificuldades de aplicação por pesquisadores/professores, visto que são identificadas ora por sua definição ora por seus critérios de delimitação em relação às demais. Daí a tentativa de sistematização que apresentamos a seguir.

A Tabela 1 contém um mapeamento das categorias para segmentação e análise de imagens em movimento a partir da articulação entre as três publicações.

Inicialmente havíamos considerado todas as categorias como sendo organizadas pelo princípio da constituência sem distinção de plano comunicativo. Seguindo esse raciocínio, tanto as categorias "gênero" e "estágio" quanto as categorias "sequência", "cena", "tomada" e "quadro" seriam partes do mesmo todo. Entretanto, do ponto de vista teórico e metodológico, é possível distinguir, nas propostas de Iedema (2001) e O'Halloran (2004), dois planos comunicativos: o plano do gênero, ou seja, da atividade social mediada pelo texto, e o plano da lexicogramática, ou seja, a estrutura peculiar das imagens em movimento como um sistema de 'linguagem'. 


\begin{tabular}{|c|c|c|c|}
\hline & $\begin{array}{l}\text { Iedema } \\
(2001)\end{array}$ & $\begin{array}{l}\text { O'Halloran } \\
\text { (2004) }\end{array}$ & $\begin{array}{l}\text { Baldry e Thibault } \\
(2007)\end{array}$ \\
\hline Recurso semiótico & - & - & Linguagem \\
\hline \multirow{4}{*}{$\begin{array}{l}\text { Plano comunicativo } \\
\text { do Gênero }\end{array}$} & - & Tipo de Filme & - \\
\hline & - & Formato do Filme & - \\
\hline & Gênero & Gênero & - \\
\hline & Estágio & Enredo fílmico & - \\
\hline \multirow{4}{*}{$\begin{array}{l}\text { Plano comunicativo } \\
\text { da lexicogramática }{ }^{4}\end{array}$} & Sequência & Sequência & - \\
\hline & Cena & Cena & - \\
\hline & Tomada & Mis-en-scène & Tomada \\
\hline & Quadro & Quadro & $\begin{array}{l}\text { Quadro Visual Imagem } \\
\text { fixa }\end{array}$ \\
\hline
\end{tabular}

Convergências

e desafios para

a pesquisa com

imagens em

movimento sob

a perspectiva

da análise

do discurso

multimodal

Tabela 1. Articulação entre três propostas para análise de imagens movimento ${ }^{5}$

Essa distinção é importante pois permite que reflitamos até que ponto as categorias propostas no plano da lexicogramática são adequadas para a descrição da estrutura e do sentido em quaisquer gêneros que empreguem imagens em movimento ou são peculiares ao gênero filme, que foi objeto de análise em Iedema (2001) e O'Halloran (2004), e teriam de ser adaptadas ou repensadas para outros gêneros.

Em seguida, apresentaremos uma discussão detalhada da equivalência entre as categorias propostas por Iedema (2001), O'Halloran (2004) e Baldry e Thibault (2007) para a análise de imagens em movimento, mantendo-nas circunscritas às categorias do plano da lexicogramática. Assim, a discussão está organizada da menor - Quadro - para a maior unidade de análise - Sequência. Em maior ou menor escala, essas categorias parecem generalizáveis para diferentes gêneros discursivos audiovisuais pois estão baseadas em critérios relativamente independentes do gênero discursivo analisado (por exemplo, conforme discutido mais adiante, a identificação da unidade denominada "Tomada" está baseda na presença de cortes de câmera). Já os critérios de identificação das categorias do plano comunicativo do gênero, quais sejam, "gênero"

4 Plano equivalente ao da lexicogramática que, neste artigo, está sendo estendido à análise das imagens em movimento.

5 No original em inglês: Genre, Stage, Sequence, Scene, Shot, Frame (IEDEMA, 2001); Film Type, Film Form, Genre, Film Plot, Sequence, Scene, Mise-en-scène, Frame (O'Halloran, 2004); Language, Shot, Visual Frame ou Still (Baldry e Thibault, 2007). 


\section{GracielaRabuske}

Hendges

Roséli Gonçalves

do Nascimento

e "estágio", estão necessariamente atreladas a uma análise de gênero. Esse tipo de análise identifica o principal objetivo comunicativo de uma atividade social ao mapear o padrão de organização dos estágios (conteúdo ideacional e atos de fala) que realizam um gênero discursivo, a partir de um conjunto de exemplares representativos desse gênero e da investigação do contexto (SWALES, 1990; MOTTA-ROTH, 2008; MOTTA-ROTH; HEBERLE, 2015). Assim, a identificação dos limites entre um estágio e outro em um gênero como o comercial televisivo, ou como a fábula animada, demanda estudo prévio sobre desse padrão organizacional, o que está além dos limites deste artigo.

\subsection{Quadro}

A menor unidade para análise de imagens em movimento é o Quadro, termo comum às três publicações revisadas aqui. Conforme definido por Iedema (2001), o Quadro é "uma imagem congelada de uma tomada" (IEDEMA, 2001. p.189) e funciona como uma 'fotografia marcante' e representativa do conteúdo dessa Tomada.

A Tomada, unidade de composição imediatamente superior ao quadro, não é delimitada por extensão, podendo ser de breve ou longa duração, conforme discutiremos na próxima subseção. Por essa razão, para Tomadas de longa duração, o analista pode "tirar mais de uma fotografia", isto é, decompor a tomada em mais de um Quadro a fim de representar o conjunto de sentido da Tomada (IEDEMA, 2001, p.188).

O Quadro, além de excluir os sentidos produzidos pelo movimento, apaga também significados representados pela linguagem verbal em áudio e por efeitos sonoros em geral (O’Halloran, 2004, p 118) e, nesse sentido, se distingue da Tomada (BALDRY; THIBAULT, 2007), apesar de capturar sua essência. Sendo assim, o Quadro, também chamado de imagem fixa (still) por Baldry and Thibault (2007), pode ser definido como uma transcrição da trilha visual. Em suma, o Quadro pode ser definido como uma imagem estática que fixa no tempo e no espaço o conteúdo de uma determinada Tomada. Nesse sentido, parcelar imagens em movimento na forma de Quadros significa eliminar o fluxo do movimento e a progressão da experiência representada na Tomada.

Do ponto de vista das funções da linguagem (HALLIDAY; MATTHIESSEN, 2004; 2014), os Quadros realizam visualmente os três tipos de significado: ideacional, interpessoal e textual, em termos visuais, como em imagens estáticas. Os participantes são expressos por formas ou volu- 
mes, Processos são expressos por vetores ${ }^{6}$ (KRESS; VAN LEEUWEN, 2006; BALDRY; THIBAULT, 2007, p. 225), e Circunstâncias pelo cenário. A interação com o espectador é realizada pelo contato visual, pela distância do enquadramento e pelo ângulo dos participantes representados em relação ao espectador e o fluxo da informação é realizado pela distribuição das informações no espaço do Quadro (centro-margem, esquerda-direita, topo-base), por marcas de saliência (tamanho, foco, iluminação), e pelo grau de conectividade entre elas (KRESS; VAN LEEUWEN, 2006).

A literatura revisada é vaga no que tange aos critérios para identificar o que é um Quadro representativo e quantos Quadros são necessários para se garantir a representatividade em caso de Tomadas extensas. Quando os autores (IEDEMA, 2001; O'HALLORAN, 2004; BALDRY; THIBAULT, 2007) definem que a seleção de um Quadro deve ser feita com Convergências e desafios para a pesquisa com imagens em movimento sob a perspectiva da análise do discurso multimodal base na sua representatividade, eles não apresentam os princípios que adotaram para selecionar os Quadros na sua própria análise.

Talvez o caminho para escolher um Quadro representativo seja identificar a função da Tomada na Cena e no texto em geral. Além disso, conforme a experiência nos tem sugerido, o propósito da pesquisa e o tipo de significado (funções da linguagem) podem funcionar como critério de representatividade.

Na Figura 2, trazemos o exemplo de dois Quadros selecionados por seu potencial de atender aos propósitos de pesquisa em Krabbe (2014), qual foss de identificar como as imagens em movimento expressam Atitude positiva e negativa no filme Melinda and Melinda, tragicomédia de Woody Allen (2005).

O Quadro 1 é representativo da Tomada 1 por sua capacidade em capturar atributos da personagem e do cenário, que contrastam com os atributos e cenário na Tomada 2. Enquanto o Quadro 1 retrata a versão de Melinda como portadora de atributos socialmente depreciados - cabelos desgrenhados, olhar baixo e cenário com iluminação fria - que expressam a Atitude negativa na Tomada trágica, o Quadro 2 congela a Tomada 2 em um momento que nos permite visualizar atributos socialmente apreciados, índices visuais de Atitude positiva.

6 Vetores são definidos como “'linhas diagonais' de direção [...], que sugerem deslocamento, ação" (MOTTA-ROTH; HENDGES, 2010, p. 57, com base em KRESS; van LEEUWEN, 2006, p.59) e "formados pela linha do olhar, braços, orientação corporal ou ainda instrumentos sugerindo movimento e/ou direção" (NASCIMENTO; BEZERRA; HEBERLE, 2011, p. 534). 


\section{GracielaRabuske}

Hendges

Roséli Gonçalves

do Nascimento

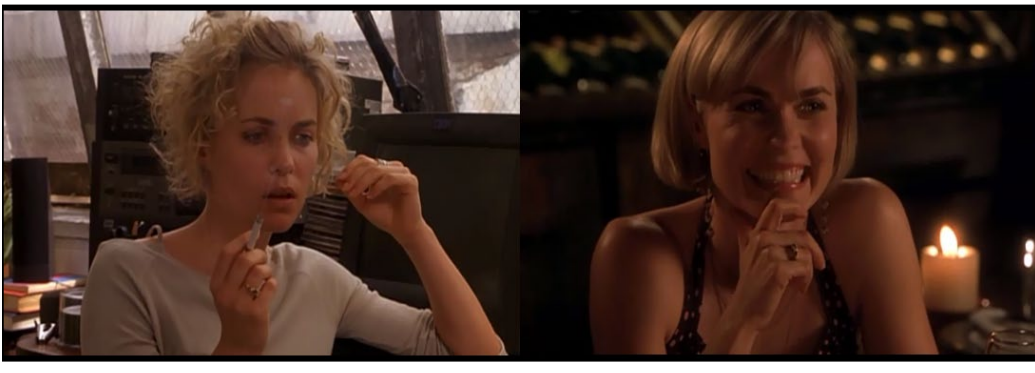

Figura 2. Quadro 1 e Quadro 2: representativos da Tomada 1 e Tomada 2, respectivamente (com base em KRABBE, 2014)

Reconhecemos que, ainda assim, recaímos na dependência do contexto, o que dificulta o estabelecimento de maior rigor científico na pesquisa em multimodalidade. Esses critérios, portanto, precisam ainda ser elaborados e testados em futuras investigações para que se tornem inteligíveis e amplamente aplicáveis tanto na pesquisa quanto na pedagogia dos multiletramentos.

\subsection{Tomada ou Mise-en-scène}

O termo Tomada é adotado por Iedema (2001) e Baldry e Thibault (2007) para nomear o componente acima do quadro. O'Halloran (2004), por sua vez, emprega a denominação Mise-en-Scène. Embora haja essa variação terminológica, todos os autores aderem ao conceito de uma unidade semântica e estrutural associada à presença de cortes de câmera. Tomadas são "ações de câmera desprovidas de cortes" (IEDEMA, 2001, p. 189), constituindo o que Baldry and Thibault (2007, p. 187) definem como as "uma sequência visual filmada na qual não há deslocamento espacial de câmera", ou seja, não há "cortes de edição" (IEDEMA, 2001, p. 189). O autor lembra, entretanto, que pode haver movimentos de câmera em termos de, por exemplo, aproximação ou afastamento, panorâmica ${ }^{7}$ e acompanhamento ${ }^{8}$.

A Figura 3 contém exemplo de uma Tomada da fábula animada "A cigarra e a formiga", produzida por Walt Disney 9 .

\footnotetext{
7 Movimento efetuado horizontalmente com a câmera, geralmente em velocidade lenta, de um lado para outro (panning, em inglês).

8 Movimento de câmera, quando apoiada em suporte tipo dolly, para frente ou para trás com o sentido de aproximar ou acompanhar um objeto ou pessoa.

9 Disponível em https://www.youtube.com/watch?v=IezC65lMZKY.
} 


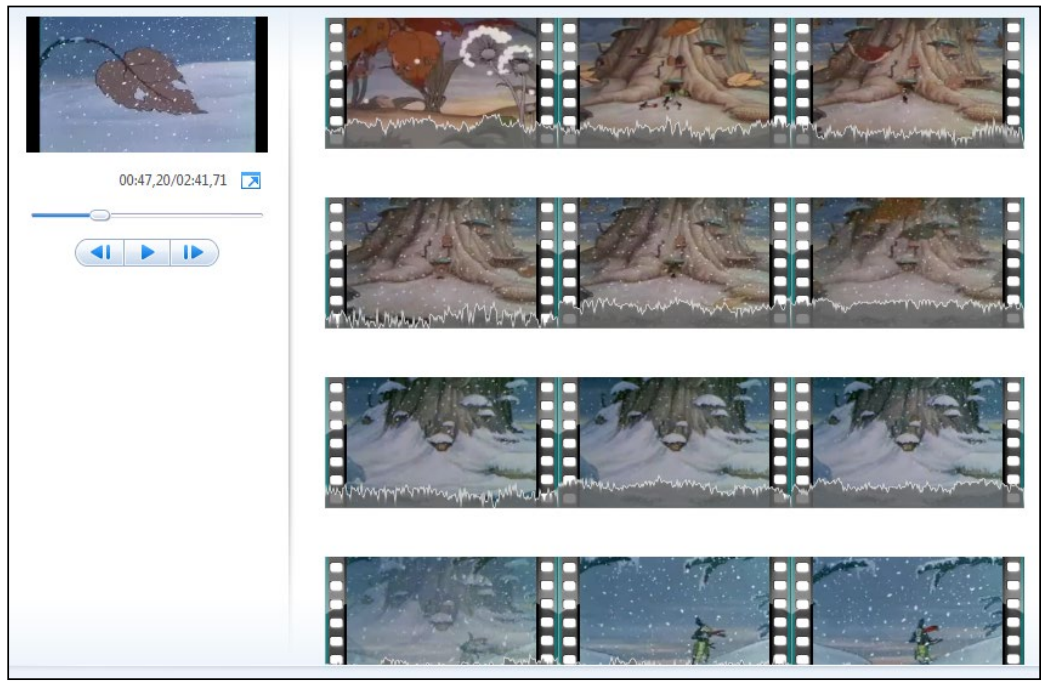

Convergências e desafios para a pesquisa com imagens em movimento sob aperspectiva da análise do discurso multimodal

Figura 3. Exemplo de Tomada na fábula animada "A Cigarra e a formiga"

Essa Tomada (Figura 3) localiza-se no estágio do Gênero fábula identificado como Problema (Situação^ Problema $^{\wedge}$ Resolução^ Fechamento/Moral - com base em FARENCENA; FUZER, 2012), que retrata a chegada do inverno e suas consequências negativas para a cigarra. O Quadro 1 (Figura 3) ainda faz parte da Tomada anterior, que realiza o prenúncio da complicação (queda das folhas e movimentos dos ventos, e, no áudio, uivo dos ventos e mudança para uma trilha musical dramática). Aos 4:3010 minutos, observamos um corte por meio de crossfade ${ }^{11}$, que marca a troca entre Tomadas. A nova Tomada é um segmento de 18 segundos (4:30 a 4:48) que narra um conjunto de eventos situados ao pé do tronco onde moram as formigas: folhas carregadas pelo vento, carreiras de formigas deslocando-se apressadamente para dentro do tronco, nevasca, até que todo o local esteja despovoado e coberto de neve. Na Figura 3, essa Tomada compreende os Quadros 2 a 10. No Quadro 10, observamos novo crossfade e, assim, o corte que marca o fim da Tomada atual e início de uma nova.

O'Halloran (2004, p. 117) define Mise-en-scène ou Tomada como “[t]udo o que é visualizado em uma gravação na medida em que ela se desdobra ao longo do tempo juntamente com a trilha sonora" desde

10 As anotações de tempo do vídeo são aproximadas e relativas exclusivamente à versão sob análise (ver nota n. 7).

11 Edição que faz uma transição suave entre dois arquivos de áudio ou vídeo. 


\section{Graciela Rabuske \\ Hendges \\ Roséli Gonçalves \\ do Nascimento}

que não haja novo disparo de câmera. Para essa autora (2004, p. 118), uma mesma Mise-en-scène pode apresentar mudanças na trilha sonora. Não havendo interrupção na gravação, a troca na trilha sonora pode ser considerada fenômeno equivalente às orações encaixadas, nas quais uma unidade funciona dentro de outra de mesmo nível (HALLIDAY; MATTHIESSEN, 2014, p. 127), como ocorre, por exemplo, quando uma oração exerce a função de grupo nominal dentro de outra oração.

Um aspecto importante levantado por O'Halloran (2004) é que a Tomada - e não o Quadro - deve ser a unidade mínima para análise de imagens em movimento. Como esclarecemos na subseção anterior, ao reduzir imagens em movimento a Quadros - imagens estáticas - eliminamos a natureza dinâmica das imagens em movimento e esse procedimento pode influenciar o resultado de análises de gêneros discursivos que levam em conta o impacto da mídia (por exemplo, do vídeo ou impressa) sobre o significado, uma vez que cada recurso semiótico tem suas potencialidades e limitações, ou sua especialidade funcional (KRESS, 1997), para expressar determinados significados. Como argumenta Van Leeuwen (1996, p. 81), “[a] linguagem das imagens em movimento tem muito em comum com aquela das imagens estáticas, mas também tem suas próprias características distintas". Por exemplo, nas imagens estáticas, as ações são realizadas por vetores que simulam movimento (como se um evento em andamento tivesse sido congelado no tempo e no espaço ao ser capturado pela câmera), enquanto que, nas imagens em movimento, as ações são realizadas pelo próprio movimento (Idem, p. 82). O'Halloran (2004, p. 117-118) explica:

\footnotetext{
A Mise-en-scène forma a unidade básica para análise porque os principais sistemas para cada metafunção estão em atividade em todos os recursos semióticos nesse nível. Por exemplo, o nível superior da Sequência não permite análise integrada das escolhas em todos os recursos semióticos, enquanto o nível inferior do quadro congelado no tempo exclui a análise da fala, música e outros efeitos sonoros.
} 
À luz dos conceitos e princípios apresentados nas três propostas, a Tomada é uma secção de um filme marcada por movimento contínuo e ininterrupto de câmera e que pode agregar recursos semióticos sonoros - fala, música e efeitos sonoros. O critério para parcelamento de imagens em movimento em Tomadas é, portanto, a identificação de mudanças na captura das imagens que possam ser entendidas como cortes. $O$ corte introduz uma nova Tomada.

Apesar da objetividade desse critério, nossa experiência em pesquisa com imagens em movimento tem nos colocado diante de novos desafios, como ilustra a Figura 4.

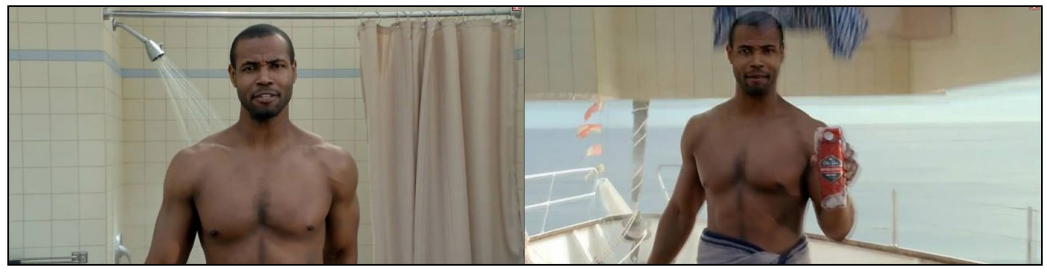

Convergências e desafios para a pesquisa com imagens em movimento sob a perspectiva da análise do discurso multimodal

Figura 4. Edição por meio de alteração incongruente do cenário

A Figura 4 traz o exemplo de um comercial de produtos de higiene masculina (SOUZA; NASCIMENTO, em preparação). A transição entre os segmentos representados pelos Quadros 1 e 2 não é feita por meio do que convencionalmente se entende por corte de câmera, mas por um recurso inusitado de "edição": a troca de cenário por meio de um efeito tipo flipchart. No Quadro A, observamos um homem com o dorso nu, toalha enrolada na cintura, representado em um banheiro. No Quadro B, observamos o início da edição com a 'subida' da parede de fundo do banheiro, relevando um fundo em ambiente aberto, de um navio no mar, e a 'descida' de uma camisa por sobre os ombros/ pescoço do homem, que aparecerá a seguir vestindo calças. A edição é explícita, altamente marcada e não é obtida por movimento de câmera, o que nos levou a considerá-la como critério para delimitação entre duas Tomadas.

$\mathrm{Na}$ ausência de melhor julgamento, acreditamos que a edição de cenário possivelmente funciona nesse caso como uma espécie de "metáfora gramatical", em que um recurso tipicamente adotado para uma função é empregado em outra. De qualquer modo, esse exemplo de pesquisa em andamento aponta para a necessidade de mais discussões no sentido de qualificar os critérios para segmentação de Tomadas. 


\section{GracielaRabuske \\ Hendges}

Roséli Gonçalves

do Nascimento

\subsection{Cena}

O nível imediatamente acima da Tomada é chamado de Cena. Esse termo é adotado em dois dos estudos revisados: Iedema (2001) e O’Halloran $(2004)^{12}$. Uma Cena, para Iedema (2001), é uma filmagem em "um único espaço-tempo, mas constituída de mais de uma Tomada (do contrário, seria uma Tomada)” (p. 189). Nos termos de O'Halloran (2004, p. 117), uma Cena é uma "série de Mise-en-scènes". Para segmentar imagens em movimento em Cenas, é necessário, portanto, observarmos dois critérios: o cenário e os diferentes movimentos de câmera. Se houver manutenção do cenário e os movimentos de câmera não caracterizarem corte, a unidade é uma Tomada. Se observarmos um ou mais cortes ao longo de um segmento, mas com manutenção do cenário, a unidade é uma Cena.

Esses dois níveis não devem ser confundidos, embora a definição de tempo-espaço "raramente seja inequívoca", conforme alerta Iedema (2001, p. 189). O autor (2001, p. 189) explica que a "decisão sobre se as Tomadas pertencem a uma mesma Cena dependerá do grau de continuidade ou descontinuidade temporal e espacial" entre as Tomadas.

Enquanto a câmera estiver filmando um cenário, a sequência de imagens que fluem são parte da mesma Cena, independentemente de cortes ou edições - Tomadas. Cenas podem ser altamente dinâmicas, em caso de vários eventos se desdobrando no mesmo cenário (IEDEMA, 2001, p. 184), ou menos densas em termos de dinamismo. Assim, se a Cena está associada à noção de “cenário” (O’HALLORAN, 2004) temporal e espacial, podemos revisitar o exemplo da Figura 4. Até que ponto, o segmento fílmico a partir do ponto zero até o ponto da troca de cenário por edição constitui uma Cena que, por sua vez, é composta de uma única Tomada? Até que ponto um segmento pode confluir duas unidades de níveis diferentes, como, por exemplo, um parágrafo constituído de uma única oração?

Um exemplo de Cena é apresentado na Figura 5.

12 Conforme se observa na Tabela 1, Baldry e Thibault (2007) não propõem unidades de composição em níveis acima da Tomada. 


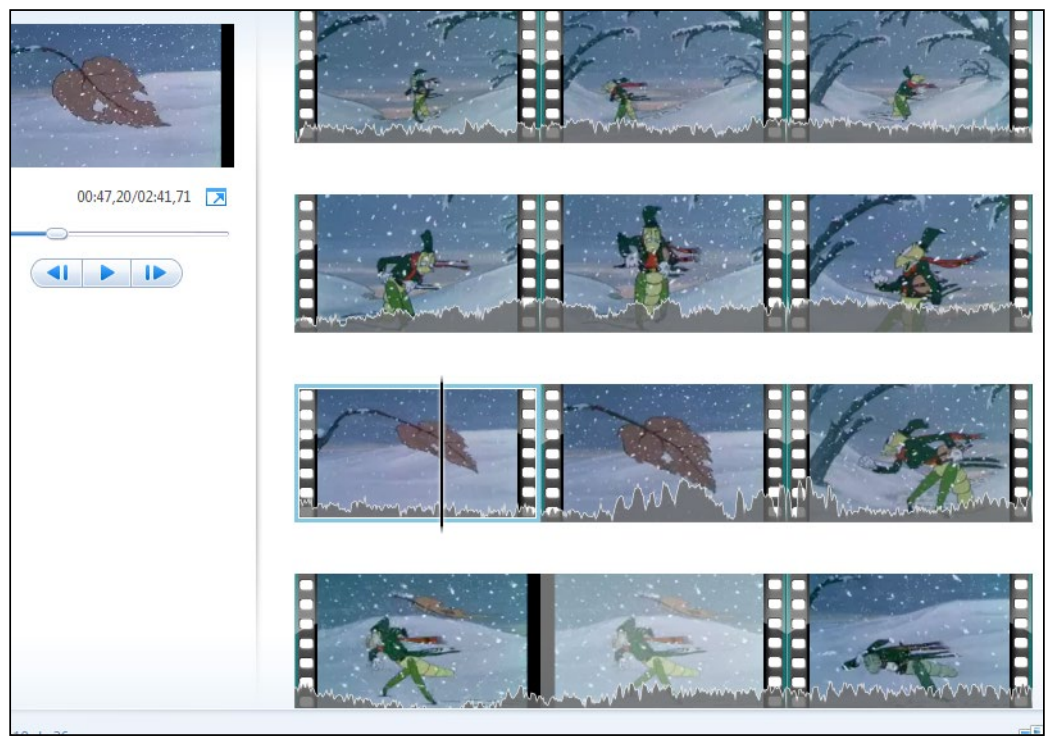

Convergências

e desafios para

a pesquisa com

imagens em

movimento sob

a perspectiva

da análise

do discurso

multimodal

Figura 5. Exemplo de Cena em “A cigarra e a Formiga” (Walt Disney)

A Cena da Figura 5 é o segmento (4:48 a 5:53) subsequente à Tomada apresentada na Figura 3. O que define esse segmento como uma Cena é que todos os eventos que se desenrolam nele situam-se em um único cenário - uma paisagem erma e nevada. Em termos de significado Ideacional, essa Cena retrata o drama da cigarra ao se confrontar com a escassez de alimento e a fome (portanto, essa Cena também realiza parte do estágio Problema na fábula). A Cena é composta de cinco Tomadas, delimitadas por edição, cada qual relatando um microevento (4:48 a 5:10, a cigarra caminha pela neve; 5:11 a 5:14, a presença da única folha/alimento no local; 5:14 a 5:19, a cigarra diz "Comida, comida!"; 5:20 a 5:27, a cigarra se desloca até a folha, que voa para longe; 5:28 a 5:53, a cigarra, faminta e com frio, caminha contra a nevasca, cai e, ao erguer a cabeça, avista algo). o limite entre esta Cena e o segmento subsequente é marcado pela troca de cenário - da paisagem erma na neve para o tronco no qual residem as formigas.

Com base na discussão anterior, uma Cena é definida, para os fins deste artigo, como um segmento de imagens em movimento que pode apresentar edições de câmera (Tomadas), desde que se mantenha no mesmo cenário. Vale destacar que essa definição adota como perspectiva analítica a linguagem visual, que assume posição privilegiada sobre o áudio na delimitação de uma unidade estrutural e semântica. Como aponta O'Halloran (2004), "a trilha sonora pode marcar uma transição" interna na unidade 


\section{GracielaRabuske \\ Hendges \\ Roséli Gonçalves \\ do Nascimento}

Tomada (Mise-en-Scène). O papel da trilha sonora em definir transições entre Cenas não é discutido na literatura revisada. Portanto, em princípio, inferimos que, para esses autores, a trilha sonora somente marca transição entre Cenas se coincidir com uma mudança no cenário, que se mantém como o critério primordial para delimitação da unidade Cena.

\subsection{Sequência}

A Sequência, termo empregado por Iedema (2001) e O'Halloran (2004), é a unidade componente do texto fílmico que encapsula um conjunto de Cenas, em outras palavras, unidades de "múltiplos espaços-tempos" (IEDEMA, 2001, p. 189). O critério que define um segmento de imagem em movimento como Sequência, no entanto, é a "continuidade temática ou lógica", e não a continuidade espacial, como ocorre com a Cena (IEDEMA, 2001, p. 189).

Para Iedema (2001), nesse nível, a câmera se move entre subtópicos e personagens, de modo que diversas Cenas são classificadas como pertencentes à mesma Sequência desde que formem uma unidade temática ou lógica (IEDEMA, 2001, p. 190), por exemplo, uma Sequência pautada pela relação lógica de causa-efeito (O'HALLORAN, 2004, p. 115).

A fim de se identificar uma Sequência, é necessário determinar um conjunto possível de relações temáticas e lógicas, processo complexo que ainda demanda especificação.

\footnotetext{
Quando é difícil decidir se você está diante de uma cena (1 tempo-espaço) ou uma sequência (múltiplos tempos-espaços), é porque os editores podem ter tornado as rupturas de espaço-tempo mais óbvias (-> fronteira da sequência) ou menos óbvias (-> fronteira da cena) (IEDEMA, 2001, p. 189).
}

Na Figura 6, apresentamos uma proposta de aplicação da categoria Sequência para segmentação das imagens na fábula animada "A cigarra e a Formiga". 


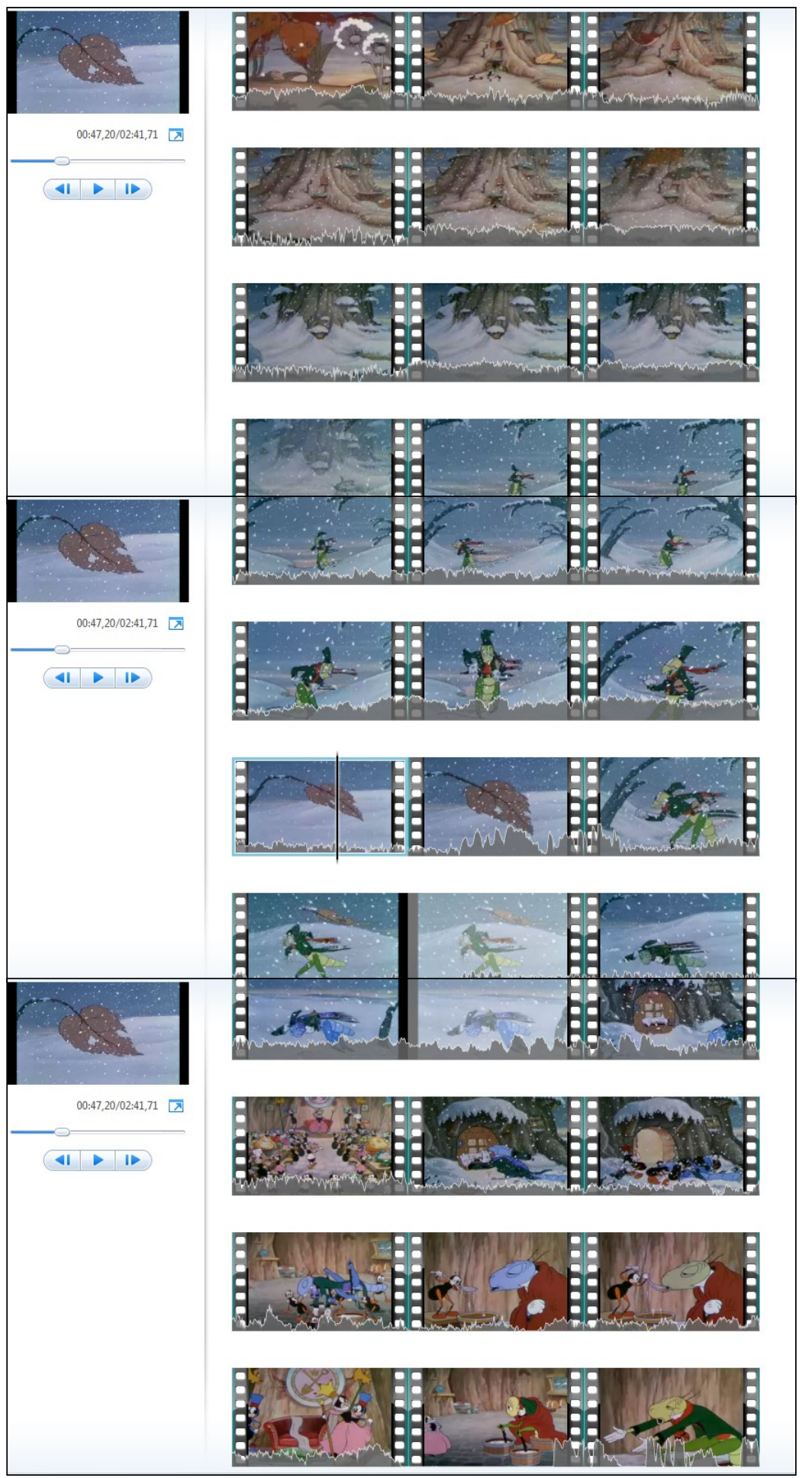

Convergências e desafios para a pesquisa com imagens em movimento sob a perspectiva da análise do discurso multimodal

Figura 6 - Exemlo de Sequência em “A cigarra e a Formiga” (Walt Disney) 


\section{GracielaRabuske \\ Hendges \\ Roséli Gonçalves \\ do Nascimento}

Com base no critério da continuidade temática, nesse exemplo, a Sequência parece confluir com o estágio genérico do Problema, instanciado nessa fábula no drama da falta de abrigo e alimento vivenciado pela cigarra com a chegada do inverno. Com base nessa interpretação, a Sequência abrangeria o segmento compreendido entre 4:30 e 7:06, representado na Figura 6 pelo conjunto dos Quadros 1 a 36. Nesse segmento, identificamos o problema e três tentativas de solucioná-lo, duas delas frustradas - a última folha (alimento) que voa para longe e o resgate frustrado pela aparente atitude de reprovação da rainha das formigas. A cigarra faz, então, uma terceira tentativa ao dizer: "Oh, Rainha, eu imploro. Tenha piedade. Não me mande para fora. Me dê uma oportunidade". A partir desse ponto, a Resolução, via reação positiva da rainha, foi considerada marco de uma nova Sequência temática.

A interpretação esboçada no parágrafo anterior aborda "tema" enquanto bloco de conteúdo ideacional mais geral, visto que está associado ao nível analítico maior da Sequência. Cabe destacar que essa interpretação não reflete necessariamente o conceito de "tema" pretendido pelos autores revisados (IEDEMA, 2001; O'HALLORAN, 2004), visto que o termo é usado imprecisamente. Semelhantemente, os tipos de "relações lógicas" que podem caracterizar as Sequências tampouco são especificados.

Parece, então, que, em textos curtos como a fábula acima, as Sequências tendem a coincidir, em parte, com os estágios do Gênero. Já textos mais longos e complexos como filmes de longa metragem, provavelmente demandem análise detalhada dos blocos temáticos e relações lógicas entre eles para identificar o nível analítico das Sequências. Por exemplo, O'Halloran (2004) argumenta que a Sequência contribui para o desenvolvimento temático do enredo de um filme. Nesse sentido, questionamo-nos até que ponto a Sequência constitui um nível composicional no plano comunicativo da "léxico-gramática" das imagens em movimento ou configura uma categoria de planos comunicativos mais abrangentes, tais como o da Semântica ou, ainda, o do Gênero.

A Tabela 2 apresenta uma síntese das categorias para análise de imagens em movimento discutidas neste artigo, para fins de referência. 


\begin{tabular}{|c|c|c|c|}
\hline Unidade & Definição & Características & $\begin{array}{l}\text { Critério(s) para } \\
\text { delimitação }\end{array}$ \\
\hline Quadro & $\begin{array}{l}\text { Imagem congelada } \\
\text { representativa do } \\
\text { conteúdo de uma } \\
\text { Tomada }\end{array}$ & $\begin{array}{l}\text { Apaga o fluxo do movi- } \\
\text { mento e a trilha sonora } \\
\text { Representatividade pode } \\
\text { depender dos objetivos } \\
\text { do analista }\end{array}$ & $\begin{array}{l}\text { Saliência e capacida- } \\
\text { de de representar o } \\
\text { conteúdo (ideacional, } \\
\text { interpessoal, textual) } \\
\text { da Tomada } \\
\end{array}$ \\
\hline Tomada & $\begin{array}{l}\text { Unidade mínima } \\
\text { para análise ima- } \\
\text { gens em movi- } \\
\text { mento e demais } \\
\text { recursos semióticos } \\
\text { combinados; } \\
\text { Segmento fílmico } \\
\text { que representa a } \\
\text { experiência em } \\
\text { uma única captura } \\
\text { de câmera e permi- } \\
\text { te análise das três } \\
\text { metafunções (idea- } \\
\text { cional, interpessoal } \\
\text { e textual) }\end{array}$ & $\begin{array}{l}\text { Inclui movimentos } \\
\text { de câmera que não } \\
\text { caracterizem cortes (por } \\
\text { exemplo, aproximação e } \\
\text { panorâmica); } \\
\text { Comporta mudanças na } \\
\text { trilha sonora, desde que } \\
\text { não haja edição por corte; } \\
\text { Mudanças na trilha } \\
\text { sonora no decorrer de } \\
\text { uma Tomada podem } \\
\text { significar 'encaixe'- uma } \\
\text { unidade encaixada em } \\
\text { outra de mesmo nível } \\
\text { hierárquico }\end{array}$ & $\begin{array}{l}\text { Presença de edições } \\
\text { que caracterizem } \\
\text { corte }\end{array}$ \\
\hline Cena & $\begin{array}{l}\text { Segmento fílmico } \\
\text { circunscrito a um } \\
\text { único espaço- } \\
\text {-tempo; } \\
\text { Pode ser altamente } \\
\text { dinâmico ao incluir } \\
\text { vários microeventos } \\
\text { que se desenvolven- } \\
\text { do no mesmo cenário }\end{array}$ & $\begin{array}{l}\text { Constitui-se de uma ou } \\
\text { mais Tomadas } \\
\text { A definição de espaço- } \\
\text {-tempo nem sempre é } \\
\text { precisa - depende de } \\
\text { graus de continuidade } \\
\text { espaço-temporal }\end{array}$ & $\begin{array}{l}\text { Continuidade do } \\
\text { cenário }\end{array}$ \\
\hline Sequência & $\begin{array}{l}\text { Segmento fílmico } \\
\text { que comporta } \\
\text { múltiplos espaços- } \\
\text {-tempos em torno } \\
\text { de uma mesma } \\
\text { temática. }\end{array}$ & $\begin{array}{l}\text { Identificação da continui- } \\
\text { dade temática ou relações } \\
\text { lógicas em grandes seg- } \\
\text { mentos é um desafio }\end{array}$ & $\begin{array}{l}\text { Manutenção do tópico } \\
\text { ou de uma relação } \\
\text { lógica (ex. Causa-efei- } \\
\text { to) entre tópicos que } \\
\text { estendem por blocos } \\
\text { iguais ou maiores que } \\
\text { uma Cena. }\end{array}$ \\
\hline
\end{tabular}

Convergências

e desafios para

a pesquisa com

imagens em

movimento sob

a perspectiva

da análise

do discurso

multimodal

Tabela 2. Síntese das quatro unidades para análise de imagens em movimento 


\section{GracielaRabuske \\ Hendges \\ Roséli Gonçalves \\ do Nascimento}

\section{Aplicações e implicações}

Neste artigo revisamos literatura prévia sobre imagem em movimento abordada do ponto de vista da Linguística Sistêmico Funcional, mais precisamente, da ADM. Esse ângulo teórico-metodológico nos interessa não só pela identidade com nosso grupo de pesquisa na Universidade Federal de Santa Maria (GrPesq CNPq "Linguagem como Prática Social”13), mas também pela preocupação que essa área tem demostrado em disponibilizar um ferramental para a pesquisa e o ensino que favoreçam os multiletramentos. Isso inclui, dentre outras coisas, o desenvolvimento de conceitos, princípios e categorias que viabilizam a descrição, explicação e interpretação (FAIRCLOUCH, 1992; 1995) dos textos que medeiam as práticas sociais contemporâneas em toda sua riqueza multissemiótica.

As três propostas - Iedema (2001), O’Halloran (2004) e Baldry e Thibault (2007) -comparadas aqui apresentam categorias para parcelamento e análise do sentido de imagens em movimento, um recurso semiótico cuja pesquisa encontra-se em um estágio subdesenvolvido, apesar da onipresença e importância desse recurso no nosso dia-a-dia.

A partir da análise, ficou evidente que há um avanço significativo na pesquisa sobre o tema, pois os autores investigados apresentam uma sintonia conceitual na proposta de quatro unidades para a análise da imagem em movimento - Quadro, Tomada, Cena e Sequência. A identificação dessas unidades contituintes e dos critérios de delimitação de cada uma são um ponto de partida crucial para a pesquisa e o trabalho com a imagem em movimento em sala de aula. Uma das caracterizações mais significativas parece ser a da Tomada, pois é defendida pelos autores como unidade mínima de análise da imagem em movimento, evitando que seja reduzida a uma série de imagens estáticas, em que são apagados efeitos semióticos criados pela dinamicidade do movimento e pela trilha sonora.

Identificamos, entretanto, alguns desafios desencadeados pelas propostas analisadas: 1 . Necessidade de refinamento dos critérios usados para a definição das unidades constituintes da imagem em movimento; 2. Necessidade padronização do princípio da constituência a partir do mesmo plano comunicativo, pois essa noção contribui para estabelecermos unidades de análise que permitam estudar a linguagem de modo criterioso e sistemático, 3. Necessidade de reflexão sobre a aplica-

13 Endereço do Grupo de Pesqusisa: http://dgp.cnpq.br/dgp/espelhogrupo/2131820406210598 
bilidade das unidades propostas para a análise e a produção de sentido por meio da imagem em movimento - por exemplo, qual a contribuição da unidade da Sequência na pesquisa e no ensino de textos com imagem em movimento? 4. Necessidade de ilustrar em que medida e como as diferentes unidades constituintes da imagem em movimento podem ser relacionadas às unidades constituintes de outros recursos semióticos (tais como morfema, palavra, grupo, oração, etc. da linguagem verbal), para fins de cruzamentos e análises intersemóticas. Esperamos que nossa discussão estimule o desenvolvimento de estudos sobre imagem em movimento para que possamos encontrar soluções para esses desafios.

\section{REFERÊNCIAS}

ALBERS, P.; SANDERS, J. Multimodal literacies: an introduction. In: ALBERS, P.; SANDERS, J. (Eds.). Literacies, the Arts and Multimodality. Urbana: National Council of Teachers of English, 2010. p. 1-25.

BALDRY, A.; THIBAULT, P. J. Film texts and genres. In: BALDRY, A.; THIBAULT, P. J. ultimodal transcription and text analysis: a multimedia toolkit and coursebook with associated online course. London: Equinox, 2006.

BATEMAN, J. A. Multimodal analysis of film within the GeM framework. Ilha do Desterro, n. 64, p. 49-84, 2013.

COPE, B.; KALANTZIS, M. "Multiliteracies": new literacies, new learning. Pedagogies: An International Journal, vol. 4, n. 3, p. 164-195, 2009.

FAIRCLOUCH, N. Critical discourse analysis. London: Longman, 1995.

FAIRCLOUCH, N. Discourse and social change. Cambridge: Polity Press, 1992.

FARENCENA, G. S.; FUZER, C. A caracterização da fábula a partir de seu Potencial de Estrutura Genológica (PEG). Linguagem \& Ensino, Pelotas, v.15, n.1, p. 65-86, jan./jun. 2012. 
GOUVEIA, C. A. M. Texto e gramática: uma introdução à linguística sistémico-funcional. Matraga, Rio de Janeiro, v.16, n.24, p. 13-47, jan./jun. 2009.

HALLIDAY, M.A.K; MATTHIESSEN, C. M. I. M. An introduction to functional grammar. 3rd ed. London: Routledge, 2004.

GracielaRabuske

Hendges

Roséli Gonçalves do Nascimento

An introduction to functional grammar. $4^{\text {th }} \mathrm{ed}$. London: Routledge, 2014.

IEDEMA, R. Analysing film and television: a social semiotic account of hospital: an unhealthy business. In: Van LEEUWEN, T. JEWITT, C. (Eds.). Handbook of visual analysis. London: Sage, 2001. p. 183-204.

JEWITT, C.; KRESS, G. (Eds.). Multimodal literacy. New York: Peter Lang, 2003.

$\mathrm{KRABBE}, \mathrm{B}$. Generic hybridism and multimodality in the film Melinda and Melinda. Trabalho de Final de Graduação. (Curso de Letras - Lic. - Hab. Inglês e Literaturas Língua Inglesa) Santa Maria, RS: Universidade Federal de Santa Maria, 2014.

KRESS, G, VAN LEEUWEN, T. Reading images: the grammar of visual design. London: Routledge, 1996.

KRESS, G, VAN LEEUWEN, T. Reading images: the grammar of visual design. 2. Ed. London: Routledge, 2006.

LEMKE, J. L. Letramento metamidiático: transformando significados e mídias. Trabalhos em Linguística Aplicada. v.49, n.2, p.455-479, 2010.

MOTTA-ROTH, D. Analise crítica de gêneros: contribuições para o ensino e a pesquisa de linguagem. DELTA, v. 24, p. 341-383, 2008.

MOTTA-ROTH, D.; HEBERLE, V. M. A short cartography of genre studies in Brazil.Journal of English for Academic Purposes, v. 19, p. 22-31, 2015.

MOTTA-ROTH, D.; HENDGES, G. R. Explorando modalidades retóricas sob a perspectiva da multimodalidade. Letras, Santa Maria, v. 20, n. 40, p. 43-66, jan./jun. 2010. 
NASCIMENTO, R. G. do; BEZERRA, F. A. S.; HEBERLE, V. M. Multiletramentos: iniciação à análise de imagens. Linguagem \& Ensino, Pelotas, v.14, n.2, p. 529-552, jul./dez. 2011.

Convergências

NASCIMENTO, R. G. do; HENDGES, G. R. Multimodalidades e gramática e desafios para visual de vídeos. I SIGATEC - I Simpósio Internacional de Games, Mundos Virtuais e Tecnologias na Educação e I Simpósio de Arte, Mídias Locativas e Tecnologias na Educação. Universidade Federal de Santa Maria, 2014.

O'HALLORAN, K. L. Multimodal discourse analysis. London/New York: Continuum, 2004. Routledge, 2003. a pesquisa com imagens em movimento sob a perspectiva da análise do discurso multimodal

SOUZA, E. S. de; NASCIMENTO, R. G. Old Spice: gender representations on TV commercials of glooming products for men (em preparação).

SWALES, J. M. Genre analysis: English in academic and research settings. Cambridge University Press, 1990.

THE NEW LONDON GROUP. A pedagogy of multiliteracies: designing social futures. Harvard Educational Review, v. 66, n. 1, p. 60-92, 1996.

VAN LEEUWEEN, T. Moving English: the visual language of film. In: GRADDOL, D. (Ed.) Redesigning English: new texts, new identities. London: Routledge, 1996. p. 81-105.

XAVIER, F. Moving image patterns of analysis from a Multimodal Discourse Analysis's perspective. Trabalho de Final de Graduação (Curso de Letras - Lic. - Hab. Inglês e Literaturas Língua Inglesa) Santa Maria, RS: Universidade Federal de Santa Maria, 2016. 
